Tropical Journal of Pharmaceutical Research January 2021; 20 (1): 203-210

ISSN: $1596-5996$ (print); 1596-9827 (electronic)

(C) Pharmacotherapy Group, Faculty of Pharmacy, University of Benin, Benin City, 300001 Nigeria.

\title{
Prescription pattern of non-steroidal anti-inflammatory drugs (NSAIDs) among community patients with musculoskeletal and co-morbid conditions: A cross- sectional study from an Iraqi province
}

\author{
Anmar Al-Taie ${ }^{1 *}$, Ali N Hussein ${ }^{2}$, Zahraa Albasry ${ }^{3}$ \\ ${ }^{1}$ Pharmacy Department, Faculty of Pharmacy, Girne American University, 99428 Kyrenia, North Cyprus, Mersin 10, Turkey, \\ ${ }^{2}$ Pharmacy Department, University College, ${ }^{3}$ Clinical Pharmacy Department, College of Pharmacy, Mustansiriya University, \\ Baghdad, Iraq \\ *For correspondence: Email: anamraltaie@gau.edu.tr
}

Sent for review: 16 June 2020

Revised accepted: 19 December 2020

\begin{abstract}
Purpose: To determine the pattern of prescription of non-steroidal anti-inflammatory drugs (NSAIDs) and proton pump inhibitors (PPIs) co-prescription with NSAIDs in a sample of patients suffering from musculoskeletal disorders with and without co-morbid cardiovascular (CV) disease conditions in Baghdad Province, Iraq.

Methods: A descriptive, cross-sectional study was conducted using a structured questionnaire to assess the clinical characteristics of patients that used NSAIDs alone or with PPIs for the treatment of different musculoskeletal disorders with and without co-morbid cardiovascular (CV) disease conditions. Results: A total of 102 participants were enrolled in the study. More than half of the participants had comorbid disease conditions (53.9 \%), particularly hypertension (47.1\%). Nearly a quarter of the participants with CV disease conditions used non-selective NSAIDs (25.5\%). The majority of NSAIDs intake were orally administered for more than one month (79.4\%). Physicians were the major source for patient education about the risk of NSAIDs-associated complications according to $59.6 \%$ of the participants. The majority of participants reported non-adherence to the prescribed PPIs (86.5\%). There was a statistically significant difference between the participants that used NSAIDs alone, and those with PPI co-prescription within the age group of $31-60$ years $(p<0.0001)$ and for a duration of more than one month for NSAIDs administration $(p<0.0001)$.

Conclusion: There is improper use of NSAIDs, particularly the non-selective agents, among patients with co-morbid cardiovascular disease conditions, as well as poor medication adherence and improper co-prescription of PPIs. This requires periodic revision for long-term intake of NSAIDs, while applying more care to high-risk patients regarding co-prescription of NSAIDs with PPIs.
\end{abstract}

Keywords: Cardiovascular, Co-morbidity, Gastrointestinal complications, NSAIDs, Proton-pump inhibitors

This is an Open Access article that uses a fund-ing model which does not charge readers or their institutions for access and distributed under the terms of the Creative Commons Attribution License (http://creativecommons.org/licenses/by/4.0) and the Budapest Open Access Initiative (http://www.budapestopenaccessinitiative.org/read), which permit unrestricted use, distribution, and reproduction in any medium, provided the original work is properly credited.

Tropical Journal of Pharmaceutical Research is indexed by Science Citation Index (SciSearch), Scopus, International Pharmaceutical Abstract, Chemical Abstracts, Embase, Index Copernicus, EBSCO, African Index Medicus, JournalSeek, Journal Citation Reports/Science Edition, Directory of Open Access Journals (DOAJ), African Journal Online, Bioline International, Open-J-Gate and Pharmacy Abstracts 


\section{INTRODUCTION}

Non-Steroidal Anti-Inflammatory Drugs (NSAIDs) are the most common anti-inflammatory and analgesic agents used for the treatment of a wide range of musculoskeletal disease conditions [1]. They act through inhibition of COX-1 and COX-2 enzymes. The inhibition of $\mathrm{COX}-1$ isoform enzyme is associated with the incidence of NSAIDs side effects, whereas inhibition of COX2 isoform enzyme is associated with their pharmacological effects, including analgesic and anti-inflammatory effects [2].

Therefore, extensive use of NSAIDs in prescriptions or short-term, low doses of overthe-counter administration has been frequently associated with many gastrointestinal tract (GIT) complications, such as dyspepsia, gut inflammation, mucosal erosions, gastric and duodenal ulcers and bleeding [3]. The mechanism of NSAIDs-induced mucosal injury involves endothelial and epithelial erosions, and direct toxicity through ion trapping and ulceration. Besides GIT adverse effects, the use of NSAIDs is associated with a range of serious complications, including cardiovascular (CV) events, renal failure and hypersensitivity reactions $[4,5]$.

Earlier studies reported that patients who use NSAIDs are four times more likely to develop uncomplicated peptic ulcer (PU) compared with non-users and $25 \%$ of chronic NSAID users. For arthritis, may develop signs of endoscopic ulcers $[6,7]$. Therefore, NSAIDs are associated with a high incidence of morbidity, particularly in elderly patients with co-morbid disease conditions, making their adverse effects a challenge in the optimized treatment of musculoskeletal disorders $[8,9]$.

Proton pump inhibitors (PPIs), through their effective role in suppression of gastric acid secretion, are one of the most important drugs used in the treatment and prophylaxis of PU disease, severe reflux oesophagitis, ZollingerEllison syndrome, stress ulceration and prevention of NSAIDs-associated gastric ulcers They have a central role in the eradication regimen of Helicobacter pylori, in combination with antibiotics, a treatment of PU disease [7,10]. The NSAIDs and PPIs are among the most frequently co-prescribed medications. Although there are no comprehensive and standard guidelines for the prescription of PPIs in NSAIDassociated ulcers, these drugs are highly effective in the prevention and treatment of NSAID-associated ulcerative complications [11]. The aim of this present study was to evaluate the pattern of prescription of NSAIDs alone, or with co-prescription of PPIs in a real-life setting in a sample of patients suffering from musculoskeletal conditions with and without CV events in Baghdad Province, Iraq.

\section{METHODS}

\section{Study design and population settings}

This was a descriptive, observational, and crosssectional study involving patients enrolled from December 2018 to February 2019. A convenient sample of participants of different age groups was selected. Patients above the age of 18 years, and those who used NSAIDs alone or with co-prescription of PPIs for treatment of different musculoskeletal disease conditions with and without CV events were included in the study. Patients with a current or history of PU disease, GIT bleeding, renal disorders and those on concomitant intake of corticosteroids were excluded. The sample size calculation was based on Cochran's sample size formula for a large population whose degree of variability is not known, and taking 95\% confidence level with $\pm 5 \%$ precision. Therefore, the required sample size with 0.35 effect size, 0.80 powers and alpha 0.05 was 105 participants.

Approval of the study was granted by the Ethical Committee of Human Research of the Pharmacy Department, Osol Aldeen University College, Baghdad Province, Iraq (03. 15.11.2018), based on the ethical standards of the Institutional Research Committee and the 1964 Helsinki Declaration and its later amendments [11]. There was no up-to-date list of community pharmacies around the time this study was performed. Therefore, a four-step sampling approach was implemented to ensure generalizability and minimize selection bias as following: the two main parts (divisions) of Baghdad Province were selected (Al-Karkh and Al-Rusafa) and each of these two parts was divided into four locations. Then, two of the most populous districts from each location were randomly selected. Finally, a convenience sample of community pharmacies was selected within each of these districts. The participants who expressed an agreement to take part in the study were fully informed about the objective of the study, and received written informed consent introduced by the researchers in the community pharmacy setting.

\section{Study outcomes}

As aforementioned, all data were collected from the community pharmacies in Baghdad Province, 
Iraq. The information was gathered via a structured, self-administered questionnaire developed for the present study, were distributed and filled by direct interview with the participants. The questionnaire was developed after a thorough and comprehensive literature search in well-known databases, and customized to suit the study purpose. The questionnaire consisted of 15 items in the data collected about the demographic and clinical characteristics of the participants, such as age, gender, educational level, cigarette smoking, the presence of comorbid disease conditions, and information about use of NSAIDs alone or with co-prescription of PPIs for treatment of different musculoskeletal disease conditions, with and without CV events.

Medication adherence to the prescribed PPIs was assessed based on 4-item Morisky Medication Adherence Scale-MMAS which comprises of four questions. The scores of this scale are based on patient responses to four questions, and patients were considered adherent when they had a maximum score of four points if they answered "no" (No = 1). While, they were considered non- adherent when they had three points or less if they answered "yes" to any question (Yes = 0) [12].

\section{Statistical analysis}

Data were analysed using Statistical Package for Social Science (SPSS) version 23.0 and Microsoft Office Excel 2013. Descriptive analysis was used to analyse the study population, and the findings for each of the study variables and characteristics are expressed in numbers, percentages, means, and standard deviations. Chi-Square Test was used to study the association between groups. Significant results were considered at $p<0.05$ and highly significant at $p<0.01$.

\section{RESULTS}

In this study, 102 participants were enrolled with a mean age of $44.1 \pm 17.5 \mathrm{y}$. The sociodemographic characteristics of the study participants are as presented in Table 1. The majority of the study participants were females (53.9 \%), and possessed university-level qualification $(43.2 \%)$ and within the group of 31 -60 y $(59.8 \%)$.

The clinical characteristics of the study participants prescribed NSAIDs are as presented in Table 2. The majority of the study participants had simultaneous occurrences of musculoskeletal and CV conditions (53.9 \%).
Hypertension (HT) and diabetes mellitus (DM) were the most common co-morbid medical conditions observed $(47.1,27 \%)$, respectively. Moreover, the findings of this study showed that $25.5 \%$ of the participants with CV conditions used non-selective NSAIDs, aside from low-dose aspirin.

Table 1: Demographic characteristics of the study participants

\begin{tabular}{|c|c|c|}
\hline Variables & Number (n) & $\begin{array}{c}\text { Percentage } \\
(\%)\end{array}$ \\
\hline \multicolumn{3}{|l|}{ Gender } \\
\hline Males & 47 & 46.1 \\
\hline Females & 55 & 53.9 \\
\hline \multicolumn{3}{|l|}{ Age range (years) } \\
\hline $18-30$ & 15 & 14.7 \\
\hline $31-60$ & 61 & 59.8 \\
\hline$>60$ & 26 & 25.5 \\
\hline \multicolumn{3}{|l|}{ Educational level } \\
\hline No formal education & 24 & 23.5 \\
\hline Primary & 15 & 14.7 \\
\hline Secondary & 19 & 18.6 \\
\hline University & 44 & 43.2 \\
\hline \multicolumn{3}{|l|}{ Cigarette smoking } \\
\hline Yes & 45 & 44.1 \\
\hline No & 57 & 55.9 \\
\hline
\end{tabular}

Table 2 shows the types and routes of administration of the prescribed NSAIDs among the study participants. The findings of the present study showed that more than three-quarter of the study participants used different oral NSAIDs, including aspirin (17 \%), ibuprofen (12.3\%) followed by $9.4 \%$ as a similar proportion for the other agents. Majority of the prescribed NSAIDs were orally administered $(79.2 \%)$ with duration of more than one month $(79.4 \%)$.

More than half of the study participants recorded having proper education about the risk of NSAIDs-associated complications. Consequently, $59.6 \%$ of those participants stated that physicians were the major source for patient education about the risk of NSAIDsassociated complications.

The present study revealed that $36.3 \%$ of the study participants prescribed PPI. Meanwhile, omeprazole was the most common PPI medication co-prescribed with NSAIDs, followed by pantoprazole $(27.9 \%)$. The majority of the study participants reported non-adherence to the prescribed PPIs medication (86.5\%), as shown in Table 3. 
Table 2: Clinical characteristics of the study participants prescribed NSAIDs

\begin{tabular}{|c|c|c|}
\hline Variables & Number (n) & Percentage (\%) \\
\hline \multicolumn{3}{|l|}{ Presence of co-morbid disease conditions } \\
\hline Yes (musculoskeletal and CV) & 55 & 53.9 \\
\hline No (musculoskeletal alone) & 47 & 46.1 \\
\hline \multicolumn{3}{|l|}{ Common types of co-morbid disease conditions } \\
\hline Diabetes Mellitus & 23 & 27 \\
\hline Hypertension & 40 & 47.1 \\
\hline Hyperlipidaemia & 8 & 9.4 \\
\hline Other CV & 14 & 16.5 \\
\hline $\begin{array}{l}\text { Use of non-selective NSAIDs in patients with CV conditions (aside } \\
\text { from low-dose aspirin) }\end{array}$ & 26 & 25.5 \\
\hline Types of the prescribed NSAIDs $(n=106)$ & 10 & 9.4 \\
\hline Naproxen & 13 & 12.3 \\
\hline Ibuprofen & 18 & 17 \\
\hline Aspirin & 10 & 9.4 \\
\hline Diclofenac & 10 & 9.4 \\
\hline Mefenamic acid & 25 & 23.6 \\
\hline Paracetamol & 10 & 9.4 \\
\hline $\begin{array}{c}\text { Meloxicam } \\
\text { Piroxicam }\end{array}$ & 10 & 9.4 \\
\hline Route of administration of the prescribed NSAIDs $(n=106)$ & 84 & 79.2 \\
\hline Oral & 7 & 6.6 \\
\hline $\begin{array}{r}\text { Parenteral } \\
\text { Rectal }\end{array}$ & 15 & 14.2 \\
\hline \multicolumn{3}{|l|}{ Duration of therapy of the prescribed NSAIDs } \\
\hline$<1$-month duration & 21 & 20.6 \\
\hline$>1$-month duration & 81 & 79.4 \\
\hline \multicolumn{3}{|l|}{ Provision of proper education about the risk of NSAIDs-associated } \\
\hline complications & 57 & 55.9 \\
\hline Yes & 45 & 44.1 \\
\hline 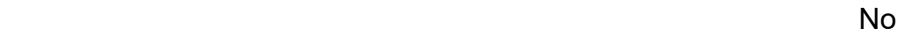 & & \\
\hline \multicolumn{3}{|l|}{$\begin{array}{l}\text { Source for the previous education about the risk of NSAIDs- } \\
\text { associated complications }\end{array}$} \\
\hline Physician advice & 34 & 59.6 \\
\hline Pharmacist advice & 23 & 40.4 \\
\hline
\end{tabular}

CV: Cardiovascular; NSAIDs: Non-steroidal anti-inflammatory drugs; Data presented in number and percentage: $\mathrm{n}, \%$

Table 3: Clinical characteristics of the study participants prescribed NSAIDs plus PPIs

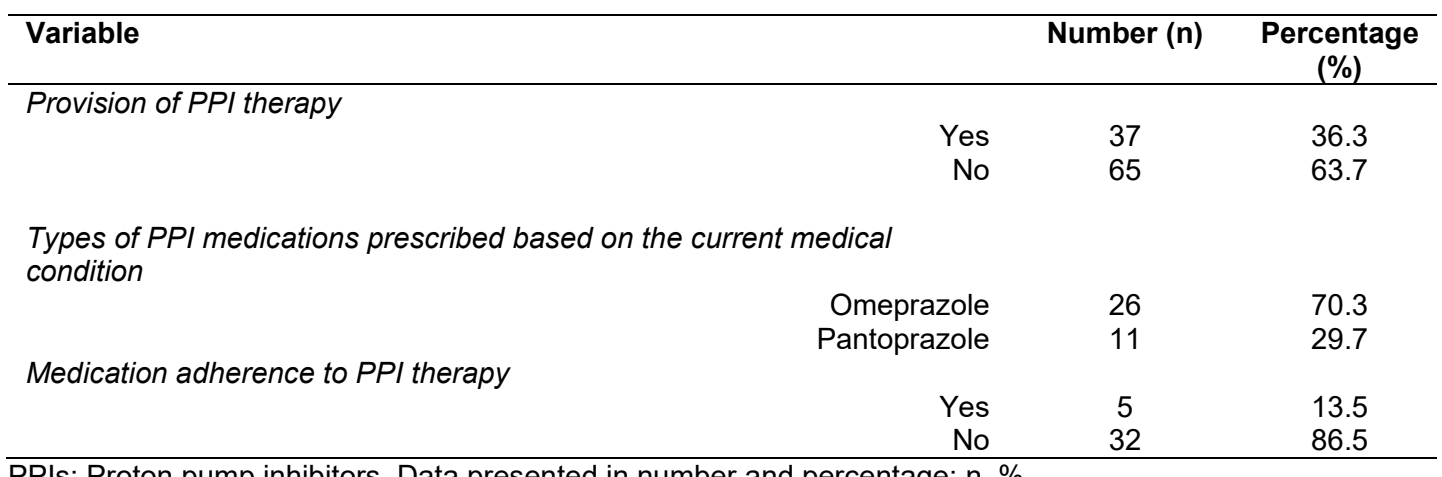

PPIs: Proton pump inhibitors. Data presented in number and percentage: $n, \%$

The present study also revealed that there was a statistically significant difference between the participants using NSAIDs alone and those with co-prescription of a PPI regarding age group of $31-60$ years $(62.3 \% ; p<0.0001)$, university education level (72.7\%; $p<0.0001)$, and duration for the administration of NSAIDs of more than one month of treatment $(66.7 \% ; p<$ 0.0001), as shown in Table 4. 
Table 4: Association between participants' characteristics and use of NSAIDs alone and NSAIDs plus PPIs

\begin{tabular}{|c|c|c|c|}
\hline Variables & $\begin{array}{l}\text { Use of NSAIDs plus } \\
\text { PPIs } \\
\begin{array}{c}\mathrm{N}=37 \\
\mathrm{n}(\%)\end{array}\end{array}$ & $\begin{array}{c}\text { Use of NSAIDs } \\
\text { Alone } \\
\mathrm{N}=65 \\
\mathrm{n}(\%)\end{array}$ & ${ }^{*} P$-value \\
\hline \multicolumn{4}{|l|}{ Gender } \\
\hline Males & $17(36.2)$ & $30(63.8)$ & 0.52 \\
\hline Females & $20(36.4)$ & $35(63.6)$ & \\
\hline \multicolumn{4}{|l|}{ Age range (years) } \\
\hline $18-30$ & $4(26.7)$ & $11(73.3)$ & $<0.0001$ \\
\hline $31-60$ & $23(37.7)$ & $38(62.3)$ & \\
\hline$>60$ & $10(38.5)$ & $16(61.5)$ & \\
\hline \multicolumn{4}{|l|}{ Educational level } \\
\hline No formal education & $11(45.8)$ & $13(54.2)$ & \\
\hline Primary & $6(40)$ & $9(60)$ & $<0.001$ \\
\hline Secondary & $8(42.1)$ & $11(57.9)$ & \\
\hline University & $12(27.3)$ & $32(72.7)$ & \\
\hline \multicolumn{4}{|l|}{ Smoking } \\
\hline Yes & $12(32.4)$ & $30(46.2)$ & \\
\hline No & $25(67.6)$ & $35(53.8)$ & 0.52 \\
\hline \multicolumn{4}{|l|}{ Presence of co-morbid medical conditions } \\
\hline Yes (musculoskeletal and CV) & $28(51)$ & $27(49)$ & \\
\hline No (musculoskeletal alone) & $9(19.1)$ & $38(80.9)$ & 0.17 \\
\hline \multicolumn{4}{|l|}{ Duration of therapy of the prescribed NSAIDs } \\
\hline$<1$-month duration & $10(47.6)$ & $11(52.4)$ & $<0.0001$ \\
\hline$>1$-month duration & $27(33.3)$ & $54(66.7)$ & \\
\hline
\end{tabular}

Data presented in number and percentage: $\mathrm{n}, \%$; highly significant at $\mathrm{P} \leq 0.01$, ${ }^{*}$ Chi square test

\section{DISCUSSION}

The NSAIDs are the most frequently prescribed drugs, and their use requires careful consideration among high-risk patients. The present study shows that the majority of the participants using NSAIDs had chronic co-morbid disease conditions, particularly HT and DM. An earlier study reported that the short or long-term use of selective and non-selective NSAIDs, excluding low-dose aspirin, is associated with increased CV risk. The use of non-selective NSAIDs in patients with pre-existing co-morbid disease conditions particularly HT could elevate systolic blood pressure by an average value of 2$3 \mathrm{mmHg}$. Therefore, BP should be regularly monitored in hypertensive patients particularly during long-term treatment. Furthermore, these drugs may double the risk of hospital admission due to heart failure (HF) in individuals with no history of CV disease conditions and 10-fold increase in patients with HF. On the other side, inhibition of platelet aggregation by the activity of selective COX-2 NSAIDs results in thrombosis and other $\mathrm{CV}$ events such as myocardial infarction (MI) $[3,13,14]$.
A cohort study by Schjerning Olsen et al [15] conducted on patients with a history of $\mathrm{Ml}$ found that the short-term use of NSAIDs increased the risk of $\mathrm{Ml}$ recurrence or death by 1.45 times, particularly during the first week of therapy, and this risk could be continued throughout the course of treatment. Many drug interactions are also reported with the use of NSAIDs in CV disease conditions, such as antagonizing the effect of antihypertensive drugs and decreasing the efficacy of diuretics. On the other hand, patients with type 2 DM should avoid NSAIDs where possible since the preservation of renal function is an essential part in the management of patients with type $2 \mathrm{DM}$, in order to prevent the development of micro- and macro-vascular complications [16].

The findings in this study reveal that the majority of the participants used different oral nonselective NSAIDs with their recommended daily dose to achieve the required analgesic and antiinflammatory response. Moreover, a quarter of the study participants with simultaneous musculoskeletal and CV disease conditions used non-selective NSAIDs. An earlier study reported that patients with CV conditions are at increased risk even after the use of selective NSAIDs, or 
after few doses of non-selective NSAIDs particularly diclofenac, which could increase the risk of Ml and/or death by 3.26 times within the first week of treatment [15]. Based on this evidence, $1 \mathrm{~g}$ daily dose of naproxen does not appear to be associated with increased CV risk. This is related to its relatively prolonged and intense inhibition of COX-1, effective platelets blocking and its ability to offset the prothrombotic effect of COX-2 inhibition [2,15]. Therefore, longer half-life NSAIDs, such as naproxen, or NSAIDs with long-acting dosage forms with once or twice daily administration are more appropriate for the treatment of chronic musculoskeletal disorders in patients with comorbid disease conditions [17].

In the present study, the majority of the prescribed non-selective NSAIDs were orally administered with their recommended daily dose for a duration of more than one month to achieve the required analgesic and anti-inflammatory response. This could increase the risk of GIT complications by 2-4 folds in a dose dependent manner, particularly in co-morbid elderly patients [17]. Therefore, topical use of NSAIDs is considered a safe alternative for treatment of musculoskeletal disorders in patients with comorbid disease conditions or NSAIDs-associated GIT complications. Alternatively, the use of relatively less gastrotoxic NSAID, such as diclofenac may be preferred in place of a more potent gastrotoxic NSAID, such as ibuprofen, indomethacin, piroxicam and naproxen [18]. However; this could go contrary to the preferred use of naproxen and the avoidance of diclofenac in patients with $\mathrm{CV}$ disease conditions. Therefore, the alternative use of selective COX-2 inhibitors, such as celecoxib, nabumatone, and etodolac is recommended for long-term NSAIDs treatment, as they have fewer gastrotoxic effetcs by 4-fold than non-selective NSAIDs. However, their use is also limited by the increased risk of poor CV outcomes [2,16].

In the present study, a high proportion of the study participants stated having proper education about the risk of NSAIDs-associated complications majorly provided by the physicians. However, considering that the majority of patients were seen in the community pharmacies, this highlights the responsibility of pharmacists to the provision of patient education for disease conditions, rational intake of drugs, enhance medication adherence, identification of drug-related problems and optimization of pharmacotherapy [19-21]. Regarding the coprescription of NSAID with PPI, the majority of the participants were non-adherent to PPI intake. Accordingly, physicians have to consider the high-risk features for GIT adverse effects while prescribing NSAIDs, including a history of a $\mathrm{GI}$ event, age above 45 years, history of CV disease conditions and simultaneous use of other medicines particularly anticoagulants, corticosteroids, aspirin, previous adverse reaction to NSAIDs and renal diseases [5].

The findings of this study showed a statistically significant difference between the participants using NSAIDs alone, and those with coprescription with a $\mathrm{PPI}$ regarding age group of 31-60 years, education level and duration of NSAIDs administration after more than one month of treatment. A survey study by Duong et al [22] found a clinically underutilized knowledge regarding the use of gastro-protective drugs with NSAIDs among internal medicine residents in several major teaching hospitals. An earlier study reported that NSAID-related GIT lesions tend to persist even after drug discontinuation, and use of alternative agent may not help in ulcers healing [23].

Therefore, less gastrotoxic NSAID can be used in patients with low GIT risk; selective COX-2 NSAID can be used in patients with a high-risk development of GIT complications or coprescribed with PPI for long-term use in treatment of musculoskeletal conditions [1,24]. PPIs should be taken on a regular daily basis, rather than on need use, in order to achieve maximum inhibition of gastric acid secretion and produce the required therapeutic effect of these drugs [25]. However, as the long-term use of PPls is associated with severe adverse effects, their prescriptions should be supported by evidence-based medicine, with the lowest effective dose and for the shortest possible duration [26].

\section{Limitations of the study}

The present study has some limitations that should be taken into account. Firstly, the study was conducted with a reduced sample size of participants. Secondly, a number of exclusion criteria such as patients with current or history of PU, GIT bleeding, renal disorders and those on concomitant intake of corticosteroids led to a reduction in the number of participants. Thirdly, the study did not include the assessment of disease duration concerning musculoskeletal conditions and medications used in patients with co-morbid disease conditions. Finally, further studies could be carried out on a large sample size to determine the impact of a pattern of NSAIDs use in patients suffering from musculoskeletal conditions with different comorbid diseases. 


\section{CONCLUSION}

The findings of the present study reveal improper use of NSAIDs, particularly the non-selective agents, and under-recognised risk of NSAIDsrelated complications among patients with comorbid cardiovascular disease conditions. The study also indicates poor medication adherence and improper co-prescription of PPIs among the patients. This requires determining true needs based on individual basis, and a periodic revision for long-term intake of NSAIDs while applying more care to high-risk patients regarding the coprescription of NSAIDs with PPIs.

\section{DECLARATIONS}

\section{Conflict of interest}

No conflict of interest is associated with this work.

\section{Contribution of authors}

We declare that this work was done by the authors named in this article and all liabilities pertaining to claims relating to the content of this article will be borne by the authors.

\section{Open Access}

This is an Open Access article that uses a funding model which does not charge readers or their institutions for access and distributed under the terms of the Creative Commons Attribution License (http://creativecommons.org/licenses/by/ 4.0) and the Budapest Open Access Initiative (http://www.budapestopenaccessinitiative.org/rea d), which permit unrestricted use, distribution, and reproduction in any medium, provided the original work is properly credited.

\section{REFERENCES}

1. McGettigan P, Henry D. Use of non-steroidal antiinflammatory drugs that elevate cardiovascular risk: an examination of sales and essential medicines lists in low-, middle-, and high-income countries. PLOS Med 2013; 10(2): e1001388.

2. Brune $K$, Patrignani $P$. New insights into the use of currently available non-steroidal anti-inflammatory drugs. J Pain Res 2015; 8: 105-118.

3. Lazzaroni M, Porro GB. Management of NSAID-induced gastrointestinal toxicity. Drugs 2009; 69(1): 51-69.

4. Sostres C, Gargallo CJ, Lanas A. Nonsteroidal antiinflammatory drugs and upper and lower gastrointestinal mucosal damage. Arthritis Res Ther 2013; 15 Suppl 3: S3.
5. Lanza FL, Chan FK, Quigley EM; Practice Parameters Committee of the American College of Gastroenterology. Guidelines for prevention of NSAIDrelated ulcer complications. Am J Gastroenterol 2009; 104(3): 728-738.

6. Hernández-Díaz S, Rodríguez LA. Association between nonsteroidal anti-inflammatory drugs and upper gastrointestinal tract bleeding/perforation: an overview of epidemiologic studies published in the 1990s. Arch Intern Med 2000; 160(14): 2093-2099.

7. Wehling M. Non-steroidal anti-inflammatory drug use in chronic pain conditions with special emphasis on the elderly and patients with relevant comorbidities: management and mitigation of risks and adverse effects. Eur J Clin Pharmacol 2014; 70(10): 1159-1172.

8. Gadzhanova S, llomaki J, Roughead EE. COX-2 inhibitor and nonselective NSAID use in those at increased risk of NSAID-related adverse events. Drugs Aging 2013; 30(1): 23-30.

9. Sachs G, Shin JM, Howden CW. Review article: the clinical pharmacology of proton pump inhibitors. Aliment Pharmacol Ther 200623 Suppl 2: 2-8.

10. Haastrup P, Paulsen MS, Zwisler JE, Begtrup LM, Hansen JM, Rasmussen S, Jarbøl DE. Rapidly increasing prescribing of proton pump inhibitors in primary care despite interventions: a nationwide observational study. Eur J Gen Pract 2014; 20(4): 290 293.

11. Declaration of Helsinki Medical Research Involving Human Subjects https://www.wma.net/what-wedo/medical-ethics/declaration-of-

helsinki/\#: :text=The\%20Declaration\%20of\%20Helsinki $\% 20(\mathrm{DoH}$, General\%20Assembly\%20in\%200ctober\%20 2013.

12. Morisky DE, Green LW, Levine DM. Concurrent and predictive validity of a self-reported measure of medication adherence. Medical Care 1986; 24(1): 6774.

13. Garcia Rodriguez L, Tacconelli S, Patrignani P. Role of dose potency in the prediction of risk of myocardial infarction associated with non- steroidal antiinflammatory drugs in the general population. J Am Coll Cardiol 2008; 52(20):1628-1636.

14. Buer JK. Origins and impact of the term 'NSAID. Inflammopharmacology 2014; 22(5): 263-267.

15. Schjerning Olsen AM, Fosbøl EL, Lindhardsen J, Folke F, Charlot M, Selmer C, Schjerning Olsen AM, Fosbøl EL, Lindhardsen J, Folke F, Charlot M, Selmer C, Lamberts $M$, Bjerring Olesen J, Køber L, Hansen PR, et al. Duration of treatment with nonsteroidal antiinflammatory drugs and impact on risk of death and recurrent myocardial infarction in patients with prior myocardial infarction: a nationwide cohort study. Circulation 2011; 123(20): 2226-35.

16. Doggen K, Nobels F, Scheen AJ, Van Crombrugge $P$, Van Casteren V, Mathieu C. Cardiovascular risk factors and complications associated with albuminuria and 
impaired renal function in insulin-treated diabetes. J Diabetes Complicat 2013; 27(4): 370-375.

17. Massó González EL, Patrignani P, Tacconelli S, García Rodríguez LA. Variability among nonsteroidal antiinflammatory drugs in risk of upper gastrointestinal bleeding. Arthritis Rheum 2010; 62(6): 1592-601.

18. Massey T, Derry S, Moore RA, McQuay HJ. Topical NSAIDs for acute pain in adults. Cochrane Database Syst Rev 2010; (6): CD007402.

19. Al-Taie A, Köseoğlu A. Incidence of early relatedcomplications of port-A catheter and impact of clinical pharmacist participation and counselling outcomes. $J$ Young Pharm 2018; 10(2): 218-21.

20. Al-Taie A, Köseoğlu A. Determination of radiotherapyrelated acute side effects; a starting point for the possible implementation of a clinical pharmacy services in the radiological unit in turkey. J Young Pharm 2019; 11(4): 434-38.

21. Al-Taie A, Abdulrazzaq HA, YIImaz ZK, Izzettin FV, Koramaz N, Yılmaz K C. Differences in patients' selfreporting types to adverse symptomatic events. Eur $J$ Clin Pharm 2016; 18(2): 130-35.
22. Duong N, Lee A, Lewis JH. Knowledge and Attitudes of Internal Medicine Trainees' Co-Prescribing Patterns of Gastroprotective Agents in Patients Taking Long-Term Non-Steroidal Anti-Inflammatory Drugs (NSAIDs). J Clin Gastroenterol Treat 2018; 4(3): 062.

23. Tachecí I, Bradna P, Douda $T$, Baštecká $D$, Kopáčová $M$, Rejchrt S, Bureš J. NSAID-induced enteropathy in rheumatoid arthritis patients with chronic occult gastrointestinal bleeding: a prospective capsule endoscopy study. Gastroenterol Res Pract 2013; 2013: 268382.

24. National Institute for Health and Care Excellence (NICE). Non-steroidal anti-inflammatory drugs. Manchester: NICE [cited 2020 April 10]. Available from: https://www.nice.org.uk/advice/ktt13.

25. Shin JM, Kim N. Pharmacokinetics and pharmacodynamics of the proton pump inhibitors. I Neurogastroenterol Motil 2013; 19(1): 25-35.

26. Marlicz W, Loniewski I, Grimes DS, Quigley EM. Nonsteroidal anti-inflammatory drugs, proton pump inhibitors, and gastrointestinal injury: contrasting interactions in the stomach and small intestine. Mayo Clin Proc 2014; 89(12): 1699-709. 